\title{
QUALITY LADDERS IN A RICARDIAN MODEL OF TRADE WITH NONHOMOTHETIC PREFERENCES
}

\author{
Esteban Jaimovich \\ Collegio Carlo Alberto
}

\author{
Vincenzo Merella \\ City University London \\ and University of Cagliari
}

\begin{abstract}
The North-South trade literature has traditionally explored conditions under which international trade might further magnify income disparities between the advanced North and the backward South. We show that even when no single country is initially more advanced than any other one and productivity changes are uniform and identical in all countries, trade may still be a source of income divergence when nonhomothetic preferences and quality ladders are jointly taken into account. Income divergence will be experienced when comparative advantages induce patterns of specialisation that, although initially optimal for all countries, do not offer the same scope for quality upgrading of final products. (JEL: F11, F43, O40)
\end{abstract}

\section{Introduction}

Nonhomothetic preferences have become increasingly common in models dealing with international trade and development. An important example is the North-South trade literature, which has consistently relied on them to account for the fact that richer countries tend to specialise in goods displaying high income demand elasticity (e.g., Flam and Helpman, 1987; Stokey, 1991; and Matsuyama, 2000). A central prediction in those papers is that trade may further magnify initial income disparities between richer and poorer economies because it leads to a secular decline of the terms of trade of economies that specialise in goods with low income elasticity. ${ }^{1}$ The NorthSouth literature has thus focused on a world economy where some countries have somehow historically accumulated larger amounts of capital than others. In this paper, we instead look at economies that start off with similar capital endowments, and

The editor in charge of this paper was Fabrizio Zilibotti.

Acknowledgments: We would like to thank the editor Fabrizio Zilibotti and two anonymous referees, Michael Ben-Gad, Jonathan Eaton, Maitreesh Ghatak, Alessio Moro, Nicola Pavoni, Juan Pablo Rud, Stephen Wright, and seminar participants in the Far East and South Asia Meeting of the Econometric Society (Tokyo), the Royal Economic Society Meeting (Surrey) and the DEGIT XV conference (Frankfurt) for helpful comments.

E-mail: esteban.jaimovich@carloalberto.org (Jaimovich); vmerella@city.ac.uk (Merella)

1. The idea of secular decline in the terms of trade of underdeveloped economies dates back to Prebisch (1950) and Singer (1950). 
propose a theory of trade and uneven growth that combines Ricardian comparative advantage and a novel specification of nonhomothetic preferences linked to quality differentiation in consumption.

Our theory rests on four fundamental elements. First, as in Grossman and Helpman (1991), there exists a continuum of horizontally differentiated consumption goods, each of which is available in an infinite number of quality levels, with higher qualities being increasingly costly to produce. Second, some goods offer larger scope for quality upgrading than others, in the sense that it is less costly to increase their quality. Third, individuals care about the quality of the goods they consume and, moreover, their willingness to pay for higher quality of consumption increases with their income. Fourth, countries that are similar in terms of their average productivities specialise in different goods according to their comparative advantage.

The first three elements above give room for nonhomothetic demand schedules, where the income demand elasticity of a good is tied to the specific quality in which that particular good is (optimally) traded in the market. The last element dictates the pattern of specialisation of economies which are initially equally rich and display no absolute advantage over one another. In such a framework, we show that the interplay between nonhomothetic preferences and quality upgrading may lead to income divergence when the comparative advantage leads to patterns of specialisation that display unequal scope for subsequent quality upgrading of final goods. Interestingly, this process of income divergence does not occur instantaneously, but only after an initial phase during which countries' incomes remain similar and relatively low. In particular, divergent dynamics will take place only after world income has surpassed a certain threshold, because nonhomotheticities linked to demand for quality start playing a predominant role in consumption choice only once individuals are sufficiently rich.

A crucial and novel feature of our model is the fact that quality upgrading involves a twofold phenomenon with budget reallocations taking place both within and across goods. This implies that our model features two distinct (yet interrelated) types of nonhomothetic behaviour. First, there is nonhomotheticity within goods, as increasingly richer consumers shift their expenditure shares towards higher qualities of each specific good. Second, there is nonhomotheticity across goods, as increasingly richer consumers shift their expenditure shares towards goods that offer larger scope for quality upgrading. In other words, in our model, the willingness to pay for quality of all types of consumption goods rises with income. Yet, when the cost of quality upgrading differs across goods, the process of shifting towards higherquality goods with rising income will (optimally) occur at different speeds across types goods. In turn, such uneven climbing-up-the-quality-ladder generates non-constant budget shares across types of goods, because higher qualities tend to attract growing expenditure shares as income rises.

We show that, when introduced into a general equilibrium model of international trade, the interplay between uneven quality upgrading and comparative advantage may lead to income divergence through its effect on the terms of trade. To briefly characterise this general equilibrium mechanism, take some hypothetical country $Z$ 
that specialises in the production of $\operatorname{good} x$, which exhibits high cost of quality upgrading. Our preference structure implies that quality upgrading for $x$ will be relatively insensitive to income growth. Hence, in a context of world income per head expansion, the world expenditure share on $x$ will decrease over time, shifting towards goods whose quality can be upgraded more easily. As a result, as the world income rises, $Z$ will experience a decline in its terms of trade, because the types of goods it produces display low income demand elasticity.

Our framework generates an endogenous consumption hierarchy of goods due to the interplay between (ex-ante) symmetric preferences and asymmetric scope for quality upgrading. In other words, some goods become luxuries while others do not because it is optimal for consumers to increase qualities unevenly across different goods as they become richer. This type of product cycle differs from that featured by most of the existing literature with nonhomothetic preferences, which has traditionally relied on hierarchical or " $0 / 1$ " preferences, where luxuries are (ex-ante) predetermined by some exogenously imposed order of needs. ${ }^{2}$

A closely related paper based on hierarchical preferences is Matsuyama (2000). In his model goods are ordered in terms of priority, and individuals continuously expand the consumption basket as they get richer by subsequently adding lower priority goods to it. This implies that, as world income grows, trade will favour countries that specialise in lower priority goods, and income disparities may accordingly emerge via the evolution of the terms of trade. An important difference of our model is that rising income leads to higher quality of consumption for all goods (more precisely, consumers switch to better versions of previously consumed goods instead of adding the consumption less urgent goods to their otherwise unchanged basket as in Matsuyama's model). The reason why some goods display higher income elasticity than others is that their quality can be more easily upgraded. As a consequence, although in our model a rise in world expenditure may indeed favour certain patterns of specialisation over others, this will be the endogenous outcome of uneven quality upgrading across goods exported by different economies. In addition, our model thus predicts that rising world income will lead to the appearance of new commodities (of higher quality than before) in all countries, and not only in richer ones as is the case in Matsuyama (2000). ${ }^{3}$

2. Further details on hierarchical preferences can be found in Bertola, Foellmi and Zweimuller (2006, pp. 302-320). The " $0 / 1$ " specification of preferences is due to Foellmi, Hepenstrick and Zweimuller (2008).

3. The prediction of the appearance of higher-quality commodities as world income rises is consistent with various strands of empirical evidence (e.g., Verhoogen, 2008; Iacovone and Javorcik, 2009; Brooks, 2006; Hallak and Schott, 2010; Fieler, 2007), which will be discussed in further detail in Section 4.1. We do not explicitly model how higher qualities become available in the market. Instead we simply assume that all qualities may (in principle) always be produced by competitive firms at some cost, which may vary well vary at different points in time. Foellmi, Wuergler and Zweimuller (2009) propose a closedeconomy endogenous growth model with nonhomothetic preferences, where innovation effort creates goods available in different quality levels. While their model allows a richer analysis of the dynamics of the process quality upgrading, ours delivers new insights regarding the product cycle in the context of a two-country world economy, where worldwide growth expands demand for higher qualities, possibly unevenly for different types of goods. 
An interesting exception to the trade literature with hierarchical preferences is a recent paper by Fajgelman, Grossman and Helpman (2009), who provide a model with nonhomothetic preferences and differentiated goods that can be offered in various degrees of quality. Different from ours, though, their production technology is the same for all goods. Therefore, nonhomotheticity is unrelated to the heterogeneous scope for quality upgrading across goods, which is a crucial point in our model. Finally, Taylor (1993), Alcala (2009), and Benedetti Fasil and Borota (2009) also study Ricardian models of trade with quality ladders for a continuum of differentiated types of goods; they all do it, however, within a homothetic framework.

Illustrative Historical Example: Colonial Jamaica and Pre-industrial Argentina. Situations where the mechanism proposed in this paper may have played an important role include the cases of economies for which exogenous initial geographical conditions greatly influenced their specialisation during some period in history. As an illustrative example, we take the case of colonial Jamaica and compare it to the one of pre-industrial Argentina.

From the second half of the XVII century until the first half of the XIX century, the Jamaican economy grew mainly based on the production and export of sugar from sugarcane. By 1805, Jamaica was the largest sugar exporter in the world (Higman, 2005). Given the value attributed to sugar by European consumers, during that period Jamaica was deemed probably the most important British colony in the Americas (Hall, 1959; Sheridan, 1973). Although sugar was indeed a very valuable consumption good at that time, it clearly was a type of good with very limited scope for undergoing subsequent improvements in quality. As such, according to our model, sugar was bound to eventually lose its status of luxury among consumers as their incomes would rise. ${ }^{4}$ In fact, by the second half of the XIX century, sugar began to lose its economic preeminence in the world markets and started experiencing a long phase of declining (relative) prices, which in turn seriously damaged the Jamaican economy. ${ }^{5}$

In Argentina, geographical conditions made this country exceptionally apt for the breeding of cattle and growing cereals, which constituted the main engines of its economy until 1914. The commercial production of cattle started in the late second half of the XVIII century with the appearance of the saladeros, slaughterhouses where meat would be cured by drying and salting (Newton, 1966). Salt-cured beef was a rather unsophisticated product that was mostly exported to Cuba and Brazil to feed slaves. In fact, the industry of the saladeros did not mean a big push to the

4. In that regard, Sheridan (1973) writes: "Until the late years of the 17th century English sugar consumption seems to have been confined rather closely to the wealthy sections of society. [... ] Lower income groups were reported to have used quantities of molasses, treacle and low-quality sugar to sweeten their eatables, and to make drinkable liquors. [...] During the 18th century the [physical] demand for sugar grew so rapidly among all sections of English society that few people considered it a luxury [anymore]."

5. By 1820 the GDP per head in Jamaica was 1.05 times the world average GDP per head, whereas by 1870 it equalled 0.61 the world average GDP per head. In fact, during the period 1820-1870, income per head in Jamaica fell $23.6 \%$, while the world average income per head grew $31 \%$. Data taken from Maddison (2008). 
Argentinean economy, which was at that time still a very marginal country within the world economy.

The big boom for the cattle industry in Argentina came much later, at the end of the XIX century. Unlike the sugar industry, the cattle industry had some scope for quality upgrading, in the form of chilled and frozen beef. The market size for this product, was however initially quite limited, since the transportation cost induced a huge differential in the prices of the two goods. Yet, in Europe, incomes had been continuously rising during the XIX century, thanks to the massive technological advancement that followed the advent of the Industrial Revolution. The availability of a higher-quality commodity in the cattle industry eventually attracted well-to-do European consumers, whose demand induced Argentinean firms to export large amounts of chilled and frozen beef to Europe. ${ }^{6}$ During the period 1890-1914, Argentina grew on average at rate of $5.5 \%$ yearly, becoming one of the richest countries in the world (Maddison, 2008). ${ }^{7}$ The exportation of chilled and frozen beef was undoubtedly one of the main activities that spurred this phase of fast and steady economic growth in Argentina between 1880-1914 (Rapaport, 1988).

This example illustrates how exogenous geographical conditions greatly influenced the path of GDP growth in Jamaica and in Argentina via the evolution of their exports, in the way our model would predict. Jamaica was comparatively efficient at producing sugar, while Argentina enjoyed a comparative advantage in beef production. Sugar offered very limited scope for quality improvements, which is analogous to assuming that the cost of quality upgrading for sugar products is extremely high. On the contrary, beef did offer some more scope for quality upgrading than sugar. The latter materialised in the switch from salt-cured beef production (lower-quality commodity) to chilled and frozen beef (higher-quality commodity). As predicted by our model, sugar exports initially sustained high growth in Jamaica, until rising income in the world shifted aggregate world expenditure towards goods which could be offered in higher quality degrees, such as chilled and frozen beef from Argentina. ${ }^{8}$

6. The main market for Argentinean chilled and frozen beef at that time was by far the prosperous Great Britain of end of XIX and beginning of XX century (in 1914, 83.5\% of the total Argentinean exports of chilled and frozen beef was sent to the UK). See Rapaport (1988).

7. By 1913, the GDP per head in Argentina was slightly larger than that of France and Germany, and it was 0.77 times the GDP per head in the UK. Data taken from Maddison (2008).

8. One may argue that the productivity improvement discussed in the example should be read as a rise in beef-specific productivity rather than an increase in aggregate productivity. Even that was the case, a mere change in productivity in the beef sector would not necessarily rationalise the facts illustrated in this example, as the way expenditure shares in beef would respond to it crucially depends on the price elasticity of beef demand. Therefore, variations in sectoral productivities would not necessarily affect the relative terms of trade between the two countries in such a way as to account for the increase in percapita Argentinean income relative to Jamaican observed in historical data. A related alternative argument follows from Lucas (1988), section 5. In particular, if there is faster learning by doing in beef production than in sugar production, this may have led Argentina to eventually outgrow Jamaica. This mechanism still does not explain so neatly why Argentine export markets changed so drastically (i.e., from poor slaves to wealthy English consumers) when production moved from salt-cured beef to chilled and frozen beef. 
The rest of the paper is organised as follows. Section 2 describes the setup of the model. Section 3 presents the consumer's problem, illustrating the specificities of the nonhomotheticity of demand in our model. Section 4 computes the general equilibrium in the world economy, and analyses the effects of uniform aggregate productivity growth, population growth and income inequality. Section 5 presents some illustrative empirical results consistent with the main predictions of the model. Section 6 concludes. Omitted proofs can be found in Appendix C.

\section{Structure of the Model}

We consider a world composed by two countries: the Home country and the Foreign country. For brevity, hereafter we refer to the former as $\mathrm{H}$ and to the latter as $\mathrm{F}$. These two economies share a common commodity space, defined along two distinct dimensions: horizontal and vertical. The first dimension (horizontal) designates the different types of goods (e.g., fruit products, TVs, etc.). Different goods are indexed by the letter $v$ along the space $V=[0,1]$. The second dimension (vertical) refers to the intrinsic quality of the good of each particular type $v$ (e.g., organic vs. nonorganic fruit products, LCD TVs vs. cathode ray tube TVs, etc.). For each good $v \in \mathcal{V}$, commodities are vertically ordered by the quality-index $q$ belonging to the set $Q=[1, \infty)$, where a higher $q$ denotes a higher quality. The commodity space is then given by the set $\mathcal{V} \times \mathcal{Q}=[0,1] \times[1, \infty)$, and each commodity is identified by a pair $(v, q) \in \mathcal{V} \times \mathcal{Q}$. We assume that all commodities are tradable. Additionally, we assume there are no transport costs and no tariffs affecting international trade.

\subsection{Technology}

In both $\mathrm{H}$ and $\mathrm{F}$ competitive firms produce commodities based on linear production functions in which labour represents their only variable input. Whenever it proves needed, hereafter we adopt the following notation: unstarred symbols refer to $\mathrm{H}$, starred ones to F. We let unit labour requirements vary both across goods and across qualities of each good. Also, we let unit labour requirements differ across countries. In particular, in $\mathrm{H}$ the unit labour requirement for commodity $(v, q) \in \mathcal{V} \times \mathcal{Q}$ is given by $c_{v q}=a(v) q^{\eta(v)} / \kappa$, while in $\mathrm{F}$ is given by $c_{v q}^{*}=a^{*}(v) q^{\eta(v)} / \kappa$.

The parameter $\kappa>0$ above denotes a world aggregate-productivity parameter, which can be interpreted as the global technology frontier. The functions $a(v)$ and $a^{*}(v)$ represent good-specific technological parameters, for $\mathrm{H}$ and $\mathrm{F}$ respectively, and we assume they may differ between those two economies. Finally, the function $\eta(v)$ summarises the cost elasticity of quality upgrading for each good $v$, which is assumed to be the same for both $\mathrm{H}$ and F. Henceforth, we suppose that $a(v):[0,1] \rightarrow \mathbb{R}_{++}$, 
where $a^{\prime}(\cdot) \geq 0$; analogously, $a^{*}(v):[0,1] \rightarrow \mathbb{R}_{++}$, where $a^{* \prime}(\cdot) \geq 0$. We also assume that $\eta(v):[0,1] \rightarrow \mathbb{R}_{++}$, where $\eta^{\prime}(\cdot)>0$ and $\eta(0)>1 .{ }^{9}$

In our world economy, each country will naturally specialise in those commodities they can produce more cheaply. As a result, the international price of each commodity will be given by $p_{v q}=\min \left\{c_{v q} w, c_{v q}^{*} w^{*}\right\}$, where $w\left(w^{*}\right.$, resp.) denotes the wage in $\mathrm{H}$ (F, resp.), measured in a common numeraire. Given the unit labour requirements in the two countries specified above, we can express the international price of each commodity $(v, q) \in \mathcal{V} \times \mathcal{Q}$ as follows:

$$
p_{v q}=\alpha(v) q^{\eta(v)} / \kappa
$$

where $\alpha(v) \equiv \min \left\{a(v) w, a^{*}(v) w^{*}\right\}$.

\subsection{Preferences and Budget Constraint}

Both $\mathrm{H}$ and $\mathrm{F}$ are inhabited by a continuum of individuals with identical preferences defined over the commodity space $\mathcal{V} \times \mathcal{Q}$.

We assume that individuals consume only one quality, denoted by $q_{v}$, of each type of good $v$. Let $x_{v} \in \mathbb{R}_{+}$denote the consumed quantity of commodity $q_{v}$ (i.e., the consumed quantity of good $v$ in quality $q$ ) by a representative individual from $\mathrm{H}$. This individual's preferences are summarised by the following utility function:

$$
U=\int_{\mathcal{V}} \ln C_{v} d v, \quad \text { with } C_{v}= \begin{cases}x_{v} & \text { if } x_{v}<1 \\ \left(x_{v}\right)^{q_{v}} & \text { if } x_{v} \geq 1\end{cases}
$$

where $C_{v}$ represents a quality-adjusted consumption index. ${ }^{10}$.

The utility function captures the notion that quality is a desirable feature, and that quality turns increasingly desirable as physical consumption rises. Notice that quality magnifies the utility derived from (physical) consumption only when $x_{v}>1$. This last property of (2) intends to capture the idea that individuals first seek to satisfy their basic consumption needs, and just after these basic needs are met, do they start paying attention to the quality dimension of the goods they consume. ${ }^{11}$

9. From the labour requirements functions it is apparent that qualitative upgrade is costly, which seems a natural assumption to make. Additionally, from our assumptions it follows that $\eta(v)>1$ for all $v \in \mathcal{V}$, which implies that the marginal cost of improving quality is, for each good, increasing along the quality space. In that sense, this assumption also seems quite natural, as it reflects the fact that subsequent quality improvements become increasingly costly. Finally, note that $\eta^{\prime}(\cdot)>0$, coupled with $a^{\prime}(\cdot) \geq 0$, implies that goods are sorted along the space $\mathcal{V}$ by their cost of quality upgrading.

10. The assumption of a single consumed quality for each good is posed to ease our exposition, and it corresponds to the solution that arises when assuming an infinite degree of substitution between qualities of the same goods. More precisely, the single consumed quality would still arise if we were to consider the following utility function: $U=\int_{\mathcal{V}} \ln \left[\int_{\mathcal{Q}} \max \left\{x_{v q},\left(x_{v q}\right)^{q}\right\} d q\right] d v$, where $x_{v q}$ denotes the consumed quantity of commodity $(v, q) \in \mathcal{V} \times \mathcal{Q}$

11. Technically, the unit-quantity threshold in the definition of the good-specific consumption index $C_{v}$ is adopted to avoid that marginal utility of quality is negative when the quantity of consumption is sufficiently low. 
Some additional properties about the utility function specified in (2) are worth noting. First, for each good $v$, marginal utility is unbounded above as consumption approaches zero, implying that all goods will be actively consumed in an optimum. Second, considering the hypothetical consumed quantities, $x_{v \bar{q}}$ and $x_{v q}$, of two different levels of the quality-index, $\underline{q}<\bar{q}$, for the same good $v$, the marginal rate of substitution of $x_{v \bar{q}}$ for $x_{v q}$ is non-decreasing along a proportional expansion path of $x_{v \bar{q}}$ and $x_{v q} \cdot{ }^{12}$ This last property of (2) allows demand functions to display nonhomothetic behaviour, where the rich spend a larger fraction of their income in higher-qualities than the poor.

Each individual is endowed with one unit of effective labour, which is supplied inelastically. Labour is immobile across countries. As a result, each individual in $\mathrm{H}$ supplies his entire labour endowment to domestic firms in return of a wage $w \in \mathbb{R}_{++}$. This wage represents the only source of income for the individual. Therefore, his budget constraint reads as follows:

$$
\int_{\mathcal{V}} p_{v} x_{v} d v \leq w
$$

where $p_{v} \in \mathbb{R}_{++}$denotes the (international) price of each unit of good $q_{v}$.

We define $\beta_{v} \equiv p_{v} x_{v} / w$ as the demand intensity of good $v \in \mathcal{V}$. In the optimum, given the specification in (2), the budget constraint (3) will naturally bind. It is thus straightforward to notice that demand intensities will sum up to one across goods (i.e., $\left.\int_{\mathcal{V}} \beta_{v} d v=1\right)$.

All individuals in the world face the same prices for the reproducible commodities. As a result, the analogous expressions in (2) and (3) corresponding to $\mathrm{F}$ read, respectively, as follows: $U^{*}=\int_{\mathcal{V}} \ln \left[\max \left\{x_{v}^{*},\left(x_{v}^{*}\right)^{q_{v}^{*}}\right\}\right] d v$ and $\int_{\mathcal{V}} p_{v}^{*} x_{v}^{*} d v \leq w^{*}$, where $p_{v}^{*} \in \mathbb{R}_{++}$denotes the (international) price of each unit of good $q_{v}^{*}$. (Bear in mind that, since labour is immobile, $w$ and $w^{*}$ need not be equal.)

\section{The Individual's Optimal Consumption Choice}

In this section we present the optimal consumption choice of a representative individual from $\mathrm{H}$, given the set of prices in the world economy. The results so obtained can be easily extended to an individual from F, which is done in Appendix B.

12. To see this, note the $\operatorname{MRS}\left(x_{v \bar{q}}, x_{v \underline{q}}\right)$ is defined by $\left(\partial U / \partial x_{v \bar{q}}\right) /\left(\partial U / \partial x_{v \underline{q}}\right)$ and, along a proportional expansion path, $x_{v \bar{q}}=k x_{v \underline{q}}$, with $k>0$. Then, from (2), for $x_{v \underline{q}}, x_{v \bar{q}}>1$ :

$$
\operatorname{MRS}\left(k x_{v \underline{q}}, x_{v \underline{q}}\right)=(\bar{q} / \underline{q}) k^{\bar{q}-1}\left(x_{v \underline{q}}\right)^{\bar{q}-\underline{q}},
$$

from where it is clear that, along the ray $x_{v \bar{q}}=k x_{v \underline{q}}, \operatorname{MRS}\left(x_{v \bar{q}}, x_{v \underline{q}}\right)$ is increasing in $x_{v \underline{q}}$. 
Before stating the consumer's optimisation problem, it proves convenient to state the following preliminary result:

$$
q_{v}>1 \Rightarrow x_{v}>1
$$

This result follows immediately from noting that, for all $v \in \mathcal{V}$, utility derived from consuming $x_{v} \in(0,1]$ is independent of the consumed quality $q_{v}$, while according to (1) the price of commodity $q_{v}$ is strictly increasing along the quality space. Given (4), we may then restate each good-specific quality-adjusted consumption index in (2) simply as: $C_{v}=\left(x_{v}\right)^{q_{v}}$.

Bearing in mind result (4) and the fact that $x_{v}=w \beta_{v} / p_{v}$, the individual's optimisation problem can be thus stated in terms of two sets of control variables, namely $\left\{q_{v}, \beta_{v}\right\}_{v \in \mathcal{V}}$,

$$
\begin{array}{ll}
\max _{\left\{q_{v}, \beta_{v}\right\}_{v \in \mathcal{V}}} & U=\int_{\mathcal{V}} q_{v} \ln \left(\frac{w \beta_{v}}{p_{v}}\right) d v \\
\text { subj. to: } & \int_{\mathcal{V}} \beta_{v} d v=1, \\
& q_{v} \geq 1, \quad \forall v \in \mathcal{V}, \\
& p_{v}=\alpha(v)\left(q_{v}\right)^{\eta(v)} / \kappa, \quad \forall v \in \mathcal{V} .
\end{array}
$$

The first-order conditions corresponding to (5) are stated in the Appendix A. From those first-order conditions we may obtain the following expression for each $\beta_{v}$ in the optimum

$$
\beta_{v}=\frac{q_{v}}{Q} \quad \forall v \in \mathcal{V}
$$

where $Q \equiv \int_{\mathcal{V}} q_{z} d z$ can be regarded as an aggregate index measuring the optimal consumption bundle's average quality. Equations (6) fully characterise the distribution of consumer spending across goods and its evolution as income varies. They state that the fraction of income spent on each good $v$ is determined by its optimal quality relative to the average quality of consumption. Equations (6) thus imply that the distribution of consumer spending across goods mirrors that of optimal qualities. Furthermore, they also imply that quality upgrading attracts expenditure, in the sense that goods whose quality upgrades faster see their demand intensities rise. This source of nonhomotheticity disappears only if all goods are consumed at identical quality degrees at all income levels (i.e., if $q_{v}=Q$, for all $v \in \mathcal{V}$, then $\beta_{v}=1$ would hold, for all $v \in \mathcal{V}$ ).

\subsection{Distribution of Qualities and Demand Intensities across Goods}

Given the technology in the world economy, summarised by $\kappa, \alpha(\cdot)$ and $\eta(\cdot)$, it is possible to characterise the distribution of the optimal qualities across goods according to their position within the set $\mathcal{V}$. Lemma 1 provides the first result in that direction. 
Lemma 1. Consider two goods $\underline{v}, \bar{v} \in \mathcal{V}$, such that $\underline{v}<\bar{v}$. Then $q_{\underline{v}} \geq q_{\bar{v}}$, with strict inequality iff $q_{\underline{v}}>1$.

Lemma 1 implies that the consumed quality $q_{v}$ is non-increasing in the good-index $v$. The underlying intuition for Lemma 1 is straightforward: those goods which can be more cheaply upgraded tend to be optimally consumed in higher quality degrees.

The monotonicity of $q_{v}$ implied by Lemma 1 allows us to split the goods space in two disjoint subsets. The first subset containing goods that are bound to be consumed at the baseline quality (i.e., $q_{v}=1$ ) - these are the higher-indexed goods. The second one comprising the goods for which the constraint $q_{v} \geq 1$ in (5) does not bind in the optimum - these are the lower-indexed goods. Henceforth, we denote the second subset by $\mathcal{L} \subseteq \mathcal{V}$.

Lastly, regarding the distribution of the demand intensities, from the condition in (6) we can observe that, in the optimum, demand intensities are set proportional to the optimal qualities. As a result, the distribution of $\beta_{v}$ across goods will qualitatively mirror that of $q_{v}$.

\subsection{Effects of Aggregate Productivity Growth on Demand}

In this section we study the effects of letting the parameter $\kappa$ vary, while holding unchanged the functions $a(\cdot), a^{*}(\cdot)$ and $\eta(\cdot)$, along with $w$ and $w^{*}$. The consequence of this is letting the consumer's real income increase, without altering any of the relative prices of commodities in the space $\mathcal{V} \times \mathcal{Q}$.

For sufficiently low levels of aggregate productivity, the subset of goods consumed at the baseline quality initially comprises the entire set $\mathcal{V}$; formally, $\mathcal{L}=\emptyset$ holds when $\kappa$ is below the threshold $\underline{\kappa} \equiv a(0) \exp (\eta(0))$. As world aggregate productivity rises beyond the threshold $\underline{\kappa}$, the subset $\mathcal{L}$ starts expanding, and eventually $\mathcal{L}=\mathcal{V}$ holds when $\kappa$ is sufficiently large. ${ }^{13}$

The next lemma complements Lemma 1 and describes in further detail how optimal qualities evolve as the parameter $\kappa$ changes.

LEMMA 2. Let $\mathcal{L}=\left\{v \in \mathcal{V}: \lambda_{v}=0\right\}$, where $\lambda_{v}$ is the Lagrange multiplier associated to the constraint $q_{v} \geq 1$. That is $\mathcal{L}$ denotes the set of goods not bound to be consumed at the baseline quality level, $q_{v}=1$. Consider two goods $\underline{v}, \bar{v} \in \mathcal{V}$, such that $\underline{v}<\bar{v}$. Then:

(i) for all $\kappa \in(0, \underline{\kappa}), \partial q_{\underline{v}} / \partial \kappa=\partial q_{\bar{v}} / \partial \kappa=0$;

(ii) for all $\kappa \geq \underline{\kappa}, \partial q_{\underline{v}} / \partial \kappa \geq \partial q_{\bar{v}} / \partial \kappa$, with strict inequality if $\underline{v} \in \mathcal{L}$.

Lemma 2 shows that, whenever $\mathcal{L}$ is non-empty (i.e., case $i i$ in the lemma), the consumed quality increases for all goods belonging to $\mathcal{L}$ as worldwide productivity rises. Furthermore, this effect is stronger for those goods whose quality can be more

13. For a formal proof of these results, see Lemma D.1 in Appendix D (online appendix). 
cheaply upgraded - i.e., those goods carrying a lower $\eta(v)$. On the other hand, we can observe that the optimal quality of goods that do not belong to $\mathcal{L}$ does not respond to (infinitesimal) changes in $\kappa$.

We can accordingly identify two distinct regimes depending on the level of $\kappa$ that prevails. First, we refer to an economy with $\kappa \leq \underline{\kappa}$ as a subsistence economy. In a subsistence economy, all goods are consumed at the baseline quality. Second, we refer to an economy with $\kappa>\underline{\kappa}$ as a modern economy. In a modern economy some goods (and possibly all of them) are consumed strictly above the baseline quality.

Subsistence Economy: $\kappa \leq \underline{\kappa}$. In this regime, $q_{v}=1$ holds for all $v \in \mathcal{V}$. This in turn means that $Q=1$ and $\beta_{v}=1$ must hold for all $v \in \mathcal{V}$ as well. Thus, in a subsistence economy demand intensities remain constant and equal to one for all goods as $\kappa$ increases. In that regard, a subsistence economy displays analogous behaviour to the economy discussed in Dornbusch et al. (1977), where demand schedules are homothetic across types of goods.

Modern Economy: $\kappa>\underline{\kappa}$. This regime is characterised by $q_{v}>1$ for all $v \in$ $[0, \tilde{v}(\kappa))$, where $\tilde{v}(\kappa)$ denotes the threshold $v \in \mathcal{V}$ such that $q_{v}>1$ for all $v<\tilde{v}(\kappa)$. Hence, the average quality can be written as $Q=1-\tilde{v}(\kappa)+\int_{0}^{\tilde{v}(\kappa)} q_{z} d z$, from where it follows that $\partial Q / \partial \kappa=\int_{0}^{\tilde{v}(\kappa)}\left(\partial q_{z} / \partial \kappa\right) d z>0$. Since $\partial q_{v} / \partial \kappa=0$ for all $v \notin \mathcal{L}$, then because of (6), $\partial \beta_{v} / \partial \kappa<0$ must hold for all $v \notin \mathcal{L}$. As a result, given that $\int_{\mathcal{V}} \beta_{v} d v=1$, it must thus be the case that the demand intensities of some (and possibly all) $v \in \mathcal{L}$ will increase as $\kappa$ rises. Henceforth, let $\mathcal{J}$ denote the subset of $\mathcal{V}$ comprising all those goods for which $\partial \beta_{v} / \partial \kappa>0$.

In a subsistence economy, $\mathcal{J}=\emptyset$, while in a modern economy, $\mathcal{J} \neq \emptyset$. In other words, in a modern economy the homotheticity of demand intensities across goods no longer holds, as a subset of goods whose income demand elasticity is larger than one emerges. Notice, too, that $\mathcal{J} \subseteq \mathcal{L}$, since $\partial q_{v} / \partial \kappa>0$ is a necessary condition for $\partial \beta_{v} / \partial \kappa>0$ to hold. The next proposition further characterises the behaviour of the demand intensities, $\beta_{v}$, as $\kappa$ rises.

Proposition 1. Let $\mathcal{J}=\left\{v \in \mathcal{V}: \partial \beta_{v} / \partial \kappa>0\right\}$. That is, $\mathcal{J}$ denotes the set of goods whose income elasticity is larger than unity. Consider any two goods $\underline{v}, \bar{v} \in \mathcal{V}$, such that $\underline{v}<\bar{v}$. Then

i) For all $\kappa \in(0, \underline{\kappa}): \partial \beta_{\underline{v}} / \partial \kappa=\partial \beta_{\bar{v}} / \partial \kappa=0$;

ii) For all $\kappa \geq \underline{\kappa}: \partial \beta_{\underline{v}} / \partial \kappa \geq \partial \beta_{\bar{v}} / \partial \kappa$; with strict inequality if $\underline{v} \in \mathcal{J}$.

To interpret our previous results more clearly, notice that $\mathcal{J}$ may be understood as the set of luxury goods. Since the set $\mathcal{J}$ always comprises lower-indexed goods, the luxury goods are exactly those goods whose quality $q_{v}$ is relatively high compared to the average quality $Q$. In that regard, in our model it is the (relative) quality that determines whether or not a particular goods is luxurious. 

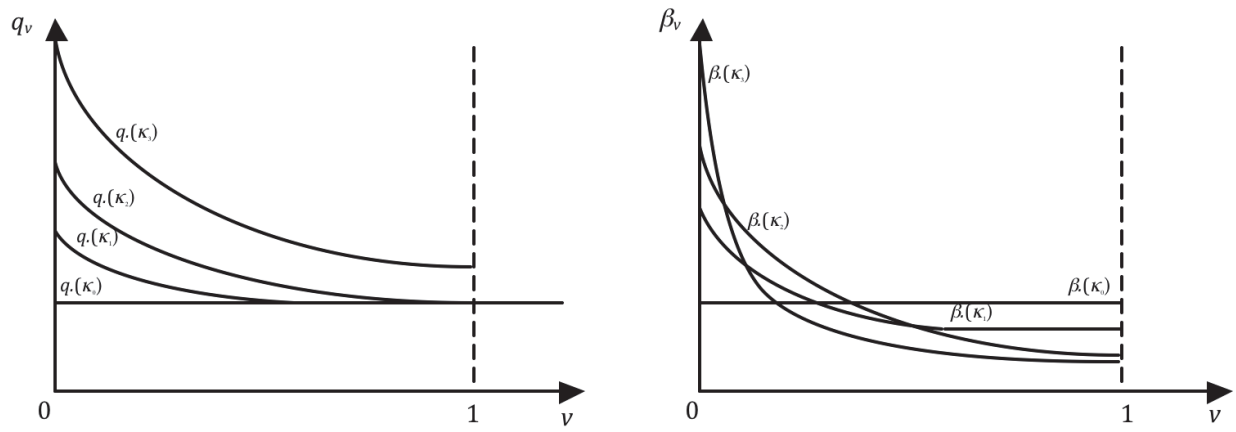

FIGURE 1. Evolution of optimal qualities and demand intensities distributions as world aggregate productivity increases.

Figure 1 illustrates this feature graphically. The distributions of qualities and demand intensities across goods are drawn for four different levels of world aggregateproductivity $\left(\kappa_{0} \leq \underline{\kappa}<\kappa_{1}<\kappa_{2}<\kappa_{3}\right)$. When individuals are still poor (i.e., for $\left.\kappa_{0} \leq \underline{\kappa}\right)$, satisfying all basic needs constitutes their main goal, leading them to keep the quality of all goods at the baseline and setting accordingly equal demand intensities for all goods. As individuals become richer, some goods - for a level of productivity $\kappa_{1} \in\left(\kappa_{0}, \kappa_{2}\right)$ - and eventually all goods - for $\kappa_{3} \geq \kappa_{2}$ - are consumed in higher qualities. As a result, for those three levels of $\kappa$, a subset of goods with $\beta_{v}>1$ appears in the lower spectrum of the (unit) goods set. Additionally, the goods whose quality is relatively higher attract increasingly larger income shares, as given the preference specification in (2) individuals tend to value high-quality commodities relatively more as they become wealthier. This last point is formalised in the following corollary.

COROllary 1. Let $\theta(v) \equiv \int_{0}^{v} \beta_{z} d z$. Then

(i) For all $\kappa \in(0, \underline{\kappa}): \partial \theta(v) / \partial \kappa=0$ for all $v \in \mathcal{V}$;

(ii) For all $\kappa \geq \underline{\kappa}: \partial \theta(v) / \partial \kappa \geq 0$ for all $v \in \mathcal{V}$, with strict inequality if $v<1$.

Corollary 1 synthesizes the eventual nonhomothetic behaviour of the demand schedules implied by our model. More precisely, whenever $\kappa<\underline{\kappa}$, demand schedules are homothetic across goods. However, when $\kappa$ lies above the threshold $\underline{\kappa}$, income starts being spent in growing proportion on lower-indexed goods.

\section{General Equilibrium in the World Economy}

In Section 3, we have studied the optimal consumption choice of an individual from $\mathrm{H}$, taking the wages in $\mathrm{H}$ and in $\mathrm{F}, w$ and $w^{*}$, as exogenously given. (In Appendix B, we do the same for the case of an individual from F.) These wages in turn determine 
the prices of all reproducible commodities in the world economy through equation (1). Our former analysis has therefore yielded only partial equilibrium results.

The present section computes the general equilibrium in this world economy. This requires endogenising wages and, thereby, the prices of all reproducible commodities. Given that in a general equilibrium only relative prices are determined, we henceforth take the wage in $\mathrm{F}$ as the numeraire, by setting $w^{*}=1$.

So far we have not put any structure in terms of comparative advantage. The next assumption dictates the pattern of comparative advantage across countries.

Assumption 1. Let $A(v) \equiv a^{*}(v) / a(v)$. We suppose: (i) $A^{\prime}(v)<0$, and (ii) there is $v_{0} \in(0,1)$ such that $A\left(v_{0}\right)=1$.

Assumption 1 represents the only source of heterogeneity across countries in our model. In particular, this last assumption implies that $\mathrm{H}$ enjoys a comparative advantage in the production of lower-indexed commodities, while $\mathrm{F}$ has a comparative advantage in the production of upper-indexed commodities.

Note that given the cost functions $c_{v q}$ and $c_{v q}^{*}$ specified in section 2.1, because $\eta(v)$ is the same for $\mathrm{H}$ and $\mathrm{F}$, the nature of comparative advantage does not change as we move up in the quality ladder. ${ }^{14}$ In that sense, in the model, the comparative advantage always refers to particular goods, irrespective of the quality at which those goods are actually produced (for example, a country that has a comparative advantage in producing fruit products, will have this advantage both in organic and in nonorganic fruit products).

From the pricing equation (1) and Assumption 1, we can derive the marginal good $m$ (that is, the good that can be supplied by both countries at the same price), which satisfies:

$$
A(m)=w .
$$

Equation (7) implies that, given the relative wage $w, \mathrm{H}$ will produce all the goods in the interval $[0, m]$ and $\mathrm{F}$ will produce all the goods within $[m, 1]$.

In order to allow countries to possibly display identical income per head in equilibrium (that is, in order to remove any direct source of absolute advantage from the model), we pose the next assumption, which formally states symmetry in terms of countries' comparative advantage.

ASSUMPTION 2 (Symmetric comparative advantages). We suppose: $v_{0}=0.5$.

Additionally, to disregard the effects of heterogeneous population size in different countries, we initially suppose that both $\mathrm{H}$ and $\mathrm{F}$ are inhabited by a continuum of individuals with identical mass, which we normalise to one. (We explore the general equilibrium effects of heterogenous population size later on in Section 4.2.)

14. Letting $\eta(\cdot)$ vary across countries change in a similar fashion as $a(\cdot)$ would not qualitatively alter the results of the paper - in fact, adding heterogeneity on $\eta(\cdot)$, on top of that on $a(\cdot)$, would reinforce our findings. 
A representative individual from $\mathrm{H}$ will then solve

$$
\begin{array}{ll}
\max _{\left\{q_{v}, \beta_{v}\right\}_{v \in \mathcal{V}}} & U=\int_{0}^{m} q_{v} \ln \left(\frac{\beta_{v} \kappa}{a(v) q_{v}^{\eta(v)}}\right) d v+\int_{m}^{1} q_{v} \ln \left(\frac{\beta_{v} \kappa w}{a^{*}(v) q_{v}^{\eta(v)}}\right) d v \\
\text { subj. to: } & \int_{\mathcal{V}} \beta_{v} d v=1 \text { and } q_{v} \geq 1 \forall v \in \mathcal{V} .
\end{array}
$$

On the other hand, a representative individual from $\mathrm{F}$ solves

$$
\max _{\left\{q_{v}^{*}, \beta_{v}^{*}\right\}_{v \in \mathcal{V}}} U^{*}=\int_{0}^{m} q_{v}^{*} \ln \left(\frac{\beta_{v}^{*} \kappa}{a(v) q_{v}^{\eta(v)} w}\right) d v+\int_{m}^{1} q_{v}^{*} \ln \left(\frac{\beta_{v}^{*} \kappa}{a^{*}(v) q_{v}^{\eta(v)}}\right) d v
$$

subj. to: $\int_{\mathcal{V}} \beta_{v}^{*} d v=1$ and $q_{v}^{*} \geq 1 \forall v \in \mathcal{V}$.

The solutions of (8) and (9) yields the demand functions of each good $v \in \mathcal{V}$ by $\mathrm{H}$ and $\mathrm{F}$, respectively. By using $\theta(v) \equiv \int_{0}^{v} \beta_{z} d z$ (as defined in Corollary 1 ) and $\theta^{*}(v) \equiv \int_{0}^{v} \beta_{z}^{*} d z$ (see Corollary B.1 in Appendix B), we can write the equilibrium condition for the market of goods produced in $\mathrm{H}$ as follows:

$$
\theta(m) w+\theta^{*}(m)=w,
$$

where $m$ is the marginal good as defined by (7). Condition (10) essentially says that the aggregate amount of income spent by the world in goods produced in $\mathrm{H}$ must be equal to the aggregate income of $\mathrm{H}$. This condition can also be understood as the equilibrium condition for the labour market in $\mathrm{H}^{15}$

The world economy general equilibrium is determined by (7), (8), (9), and (10). Henceforth, we will focus our attention on the equilibrium values of $w$ and $m$, and on how these two variables respond to some comparative statics experiments commonly explored by the previous literature on international trade with nonhomothetic preferences.

\subsection{Worldwide Uniform Aggregate Productivity Growth}

In this subsection, we look at the impact of changes in $\kappa$ on the equilibrium values of $w$ and $m$. We can split the results in two different cases.

Subsistence economies: $\kappa \leq \underline{\kappa}$. From our previous discussion, we can observe that when $\kappa \leq \underline{\kappa}$, the optimal demand intensities are set at $\beta_{v}=\beta_{v}^{*}=1$ for all $v \in \mathcal{V}$. This result in turn implies that $\theta(m)=\theta^{*}(m)=m$. Therefore, (10) simplifies to:

$$
w=m /(1-m) \text {. }
$$

15. Because of the Walras' Law, an analogous equilibrium condition can be derived for the labour market in $\mathrm{F}$. 
Combining (7) with (11), leads to $m /(1-m)=A(m)$, from where it follows that, given Assumption 2 and for all $\kappa \leq \underline{\kappa}: w=1$ and $m=0.5$. That is, $\mathrm{H}$ and $\mathrm{F}$ exhibit the same level of income, and the pattern of regional specialisation is accordingly dictated by the "natural" comparative advantage of each country without the relativewage effect (i.e., those that derive purely from Assumption 1). ${ }^{16}$

Modern economies: $\kappa>\underline{\kappa}$. When aggregate productivity is sufficiently high, the income equality between $\mathrm{H}$ and $\mathrm{F}$ no longer holds. In particular, as $\kappa$ rises above the threshold $\underline{\kappa}$, the terms of trade start moving in favour of $\mathrm{H}$, and thus $\mathrm{H}$ becomes relatively richer than $\mathrm{F}$. Moreover, the income disparity between $\mathrm{H}$ and $\mathrm{F}$ further increases as $\kappa$ keeps rising.

Proposition 2. Let $\kappa>\underline{\kappa}$. Then, in equilibrium: (i) $w>1$ and $m<0.5$; (ii) $\partial w / \partial \kappa>0$ and $\partial m / \partial \kappa<0$.

Proof. Part (i). When $\kappa>\underline{\kappa}$, from Corollary 1 and 2 it follows that $\theta(m)>m$ and $\theta^{*}(m)>m$. As a result, by using $(10)$, we can obtain,

$$
w=\frac{\theta^{*}(m)}{1-\theta(m)}>\frac{m}{1-m} .
$$

Combining next (12) with (7), and recalling Assumption 1 and 2 leads to:

$$
A(m)=\frac{\theta^{*}(m)}{1-\theta(m)}>\frac{m}{1-m} \Leftrightarrow m<0.5 .
$$

Finally, since $m<0.5$, equation (7) implies that $w>1$.

Part (ii). Next, to study how $w$ and $m$ vary as $\kappa$ keeps rising above $\underline{\kappa}$, we differentiate the equilibrium conditions (7) and (10). This leads to

$$
\frac{\partial w}{\partial \kappa}=A^{\prime}(m) \frac{\partial m}{\partial \kappa}
$$

and

$$
\begin{array}{r}
\left(w \beta_{m}+\beta_{m}^{*}\right) \frac{\partial m}{\partial \kappa}+\left(w \frac{\partial \theta(m)}{\partial w}+\theta(m)+\frac{\partial \theta^{*}(m)}{\partial w}\right) \frac{\partial w}{\partial \kappa}+\left(\frac{\partial \theta(m)}{\partial \kappa}+\frac{\partial \theta^{*}(m)}{\partial \kappa}\right) \\
=\frac{\partial w}{\partial \kappa}, \quad(14)
\end{array}
$$

where the first term in (14) uses the fact that $\partial \theta(m) / \partial m=\beta_{m}$ and $\partial \theta^{*}(m) / \partial m=$ $\beta_{m}^{*}$. Plugging (13) into (14), we can obtain:

$$
\frac{\partial m}{\partial \kappa}=\frac{\frac{\partial \theta(m)}{\partial \kappa}+\frac{\partial \theta^{*}(m)}{\partial \kappa}}{\left[1-\theta(m)-w \frac{\partial \theta(m)}{\partial w}-\frac{\partial \theta^{*}(m)}{\partial w}\right] A^{\prime}(m)-\left(w \beta_{m}+\beta_{m}^{*}\right)}
$$

16. Notice that, since $w=1$ for all $\kappa \leq \underline{\kappa}$, in fact $\underline{\kappa}=\underline{\kappa}^{*}$ (that is, the threshold on $\kappa$ that divides a subsistence-economy from a modern economy happens to be the same for both $\mathrm{H}$ and F). As a consequence, we can refer to both thresholds simply as $\underline{\kappa}$. 
To determine the sign of (15), we can use the following two results: first, Corollary 1 states that both $\partial \theta(m) / \partial \kappa>0$ and $\partial \theta^{*}(m) / \partial \kappa>0$; second, as shown in Appendix D (online appendix), $\partial \theta(m) / \partial w \leq 0$ and $\partial \theta^{*}(m) / \partial w<0$. Therefore, since $1-\theta(m)>$ 0 and $A^{\prime}(m)<0, \partial m / \partial \kappa<0$ obtains from the right-hand side of (15). Finally, from (13) it then follows that $\partial w / \partial \kappa>0$.

Proposition 2 shows that as the world aggregate-productivity parameter, $\kappa$, increases, the income in $\mathrm{H}$ eventually begins diverging away from the income in $\mathrm{F}$. The reason for the divergence rests on the fact that $\mathrm{H}$ enjoys a comparative advantage in producing lower-indexed goods, which tend to be consumed in relatively higher qualities and display accordingly higher income demand elasticity. As a consequence, as the world productivity grows uniformly above $\underline{\kappa}$, aggregate world expenditure shifts towards the set of commodities produced by $\mathrm{H}$. The ensuing excess demand for commodities produced in $\mathrm{H}$ causes excess labour demand in $\mathrm{H}$ and $w$ thus goes up. In turn, as $w$ rises, the marginal good moves to the left (i.e., $m$ falls), and some of the goods that used to be produced by $\mathrm{H}$ start being produced by $\mathrm{F}$, restoring the equilibrium in the labour markets.

An interesting feature of our model is that income disparities take time to arise. The reason is that the comparative advantage in quality upgrading by $\mathrm{H}$ does not materialise at low levels of income per head in the world economy. As a result, $\mathrm{H}$ and $\mathrm{F}$ display initially (and for some time) the same level of income per head. Sectorial productivities do differ across the two countries, and they in fact govern the patterns of regional specialisation. Yet, this heterogeneity is not enough to warrant income disparities between $\mathrm{H}$ and $\mathrm{F}$, because at low levels of income per head the willingness to pay for high-quality commodities is not large enough to tilt aggregate demand disproportionately towards the goods produced by H. However, in a context where incomes continuously rise, goods exhibiting larger scope for quality upgrading will eventually become increasingly appreciated by consumers and, thus, will start absorbing growing budget shares. Within a general equilibrium framework, this mechanism implies that aggregate demand will eventually shift towards $\mathrm{H}$, inducing thus faster income growth in $\mathrm{H}$ relative to $\mathrm{F}$, via the secular tendency to improve H's terms of trade.

Concerning the evolution of the world productive structure, the equilibrium adjustments triggered by worldwide uniform productivity growth generates two types of product cycle phenomena. First, the marginal good, $m$, shifts left: this is an international product cycle phenomenon involving both countries simultaneously, similar to that in Linder (1961) and Vernon (1966), where over time the production of lower-quality goods moves from $\mathrm{H}$ to $\mathrm{F}$, while $\mathrm{H}$ specialises in more sophisticated higher-quality goods. The second phenomenon occurs within each good and could be denoted regional product cycle, as it involves single countries individually: rising world income leads both $\mathrm{H}$ and $\mathrm{F}$ to abandon the manufacturing of lower-quality goods and replace them with the production of goods of higher quality (i.e., the optimal $q_{v}$ tends to rise for all goods traded in the world economy as $\kappa$ increases). 
An implication of the regional product cycle phenomenon is the fact that citizens from $\mathrm{H}$, who are richer than those from $\mathrm{F}$, consume comparatively higher qualities for each good traded in the international markets; i.e. $q_{v} \geq q_{v}^{*}, \forall v \in \mathcal{V}$. This result is consistent with various strands of empirical evidence. For instance, Verhoogen (2008) and Iacovone and Javorcik (2009) show that Mexican manufacturing plants produce higher-quality versions of goods to export to richer markets (mainly the US). Similar evidence is provided by Brooks (2006) for Colombian manufacturing plants. A more general piece of evidence emerges from Hallak and Schott (2010) who using crosscountry data show that the quality gap in production between rich and poor economies is smaller than their income gap, which suggests that poorer economies are producing high-quality goods to sell in richer markets. The same conclusion follows from Fieler (2007) who reports that unit prices (a proxy for quality) rise with the importer's income per capita, even for goods originating from the same exporter and commodity category. ${ }^{17}$

Further Discussion. Our previous results are derived from a largely stylised model. The main insights will hold, nonetheless, under more general assumptions regarding preferences and technology. Concerning our preference specification, the essential feature is that the marginal utility of quality upgrading rises with income fast enough relative to the marginal cost of quality upgrading. With respect to the technology itself, somewhat restrictive assumptions such as: (i) the monotonicity of $A(v)$ in Assumption 1 or (ii) the fact that functions $a(v)$ and $a^{*}(v)$ are both increasing in $v$, could be relaxed. A non-monotonic $A(v)$ will certainly lead to richer general equilibrium responses to worldwide technological growth. Yet, the key finding that the economy specialising in the goods with lowest cost of quality upgrading will eventually experience faster growth through the improvement of its terms of trade would still obtain. On the other hand, letting $a(v)$ and $a^{*}(v)$ behave in an unrestricted way may give rise to changes and switches in the order of quality upgrading across goods. However, again, the goods with relatively low elasticity of quality upgrading -i.e. those with relatively low $\eta(v)$ - will eventually become those that experience relatively fast quality upgrading, just as it occurred in our benchmark model. ${ }^{18}$

Lastly, Assumption 2 is non crucial to our model either. Assuming that comparative advantages are symmetrically distributed between the two countries makes our argument of eventual income divergence much sharper. However, notice that the proof of result (ii) in Proposition 2 does not actually rely on Assumption 2. In fact, both $\partial w / \partial \kappa>0$ and $\partial m / \partial \kappa<0$ would still obtain if we instead gave a larger range of initial advantage to $\mathrm{F}$ by assuming that $v_{0}<0.5$. If $v_{0}<0.5$, somewhat

17. Our model fails, however, to explain the dynamics of variety expansion and productive diversification along the path of development. More precisely, our model predicts that richer economies tend to specialise in a continuously narrowing set of goods as world income rises, which is not in accord to the inverted U-shaped relationship between divesification and income per head found by Imbs and Wacziarg (2003).

18. A case of this would be the motivational historical example of Argentina and Jamaica in the Introduction. 
richer dynamics would be obtained, though. More precisely, $w<1$ would hold for levels of worldwide productivity below a certain (finite) threshold $\widehat{\kappa}>\underline{\kappa}$, while the model would predict catching-up by $\mathrm{H}$ for values of $\kappa \in(\underline{\kappa}, \widehat{\kappa})$, followed next by overtaking and divergence in an analogous fashion as it occurred when $v_{0}=0.5$.

\subsection{Uneven Population Growth}

We now let the population size in $\mathrm{F}$ differ from that in $\mathrm{H}$. In particular, we let the total mass of individuals in $\mathrm{F}$ equal $L>1$, while we keep the total mass of individuals in $\mathrm{H}$ equal to 1 . Thus, the labour market equilibrium condition in $\mathrm{H}$ will be given by

$$
\theta(m) w+L \theta^{*}(m)=w .
$$

Visual inspection on (16) and (10), combined with (7), immediately implies that the equilibrium value of $w$ that is delivered by (16) will be strictly larger than that yielded by (10). In particular, in equilibrium $w>1$, regardless of the value of $\kappa$. Furthermore, this source of income disparity between $\mathrm{F}$ and $\mathrm{H}$ magnifies as the value of $L$ rises. This is because, when the population in F increases, the relative wage $w$ must go up so as to accommodate the excess supply of labour in F. More precisely, a larger $L$ requires more goods to be produced by $\mathrm{F}$ in order to keep full employment there; this is accomplished by letting $w$ go up, which in turn shifts the marginal good $m$ to the left, helping restore the equilibrium in the labour markets.

The result that, as the relative population of $\mathrm{F}$ increases, the $\mathrm{H}$ relative wage rises is in line with Flam and Helpman (1987), Stokey (1991) and Matsuyama (2000). However, some interesting differences are also present. In Flam-Helpman and Stokey, although the optimal bundle of goods traded in the market changes, no new goods actually appear in the world economy as $w$ rises due to uneven population growth. In Matsuyama, new goods start being produced, but this happens only in the country whose population grows slower (i.e., in $\mathrm{H}$ ); the country whose population grows faster, F, does not introduce new goods into the world markets, but only takes on the production of (some) goods that are abandoned by $\mathrm{H}$ as $w$ increases. In our model, new goods actually start being produced by $\mathrm{F}$ as its relative wage decreases owing to faster population growth. A higher $w$ brings about two different effects: first, individuals in $\mathrm{H}$ become richer (income effect); second, the relative prices of the goods originally produced in $\mathrm{F}$ decline (substitution effect). Taken jointly, these two effects reinforce one another and induce individuals from $\mathrm{H}$ to start demanding higher qualities for the goods produced in $\mathrm{F}^{19}$

19. For example, our model then predicts that Africa will start to produce, say, organic bananas to sell in Europe, as increasingly richer European consumers begin desiring to purchase higher-quality fruit products, which are moreover becoming relatively cheaper over time as population in Africa grows faster than in Europe. 


\subsection{Income Inequality within Countries}

In this subsection we introduce some degree of income heterogeneity within countries. Analogous qualitative results would generated regardless of whether inequality is introduced in $\mathrm{F}$ or $\mathrm{H}$ (or in both at the same time). Therefore, for brevity, in what follows we focus only on the first case.

Assume that $\mathrm{F}$ is inhabited by two types of individuals: $p$ and $r$, where the $p$ stands for poor and $r$ stands for rich. Each sub-group of individuals from $\mathrm{F}$ has mass equal to 0.5 . The difference between the two sub-groups lies in that a type $p$ is endowed with a smaller amount of effective labour than a type $r$. In particular, suppose that type- $p$ individuals are endowed with $1-\iota$ units of effective labour and individuals in $r$ are endowed with $1+\iota$ units of it, where $\iota \in(0,1)$. On the other hand, in $\mathrm{H}$ everyone is endowed with the same amount of effective labour. Introducing income inequality in the model leads to interesting results when the types $p$ are so poor that, in equilibrium, they consume all goods at the baseline quality level, whereas in contrast the types $r$ can afford consuming at least some of the goods strictly above that level. To focus on such case, we accordingly set $\kappa=\underline{\kappa}$.

Introducing income inequality in $\mathrm{F}$ raises the relative wage in $\mathrm{H}$. This is due to the nonhomotheticity of the demand schedules of the rich foreigners. More precisely, raising $\iota$ transfers income from the poor foreigners, who spend a fraction $m$ of it in goods from $\mathrm{H}$, to the rich foreigners, who spend a fraction $\theta_{r}^{*}(m)>m$ of their income on those commodities. As a result, aggregate demand for goods produced in $\mathrm{H}$ rises, leading to higher $w$. Similarly, inequality within $\mathrm{H}$ would carry similar consequences on both $w$ and $m$. This is because the rich locals (just like the rich foreigners) would tend to shift demand towards the goods produced in $\mathrm{H}$.

\section{Quality Ladders Length and Exports Behaviour: A brief examination of the trade data}

Our open economy model predicts that, when world income per head is growing, economies specialising in the production of goods with larger scope for quality upgrading (long-ladder goods) tend to see their value of exports rise relatively more. This, in turn, implies that the income per head of countries producing long-ladder goods should grow faster as well, owing to the ensuing improvement of their terms of trade.

Evidence of a positive association between income per head and specialisation in long-ladder goods is presented in Khandelwal (2010). He estimates the length of quality ladders for different industries, showing that import penetration from poorer economies in the US is lower in industries that exhibit longer quality ladders. In addition, exports to the US originating from other developed economies tend to belong precisely to those long-ladder industries and, in particular, to the upper spectrum of their respective (long) quality ladders. Similar evidence is provided by Schott (2004) who, using unit values to measure the quality of goods, shows that US import unit 
values correlate positively with the exporter's GDP per head. Moreover, this positive correlation tends to be more pronounced for goods that exhibit larger scope for quality upgrading (e.g., manufactured goods) compared to more homogeneous goods (e.g., natural resources goods). ${ }^{20}$

Following Schott's approach of using unit prices as a proxy for quality, in this section we briefly investigate whether countries that specialise in the production of long-ladder goods tend to experience a greater rise in their exports when world income rises. ${ }^{21}$ We build two different proxies based on measures of dispersion of import unit prices using the data compiled by Feenstra et al. (2005): one using the ratio of extreme unit prices, the other one using the dispersion of unit prices. This dataset documents bilateral trade at the country level for the period 1962-2000 measured both in value and quantities, organised following the 4-digit Standard International Trade Classification (SITC-4), Revision 2. From this dataset, we calculate the (average) import unit prices of each SITC-4 product by each importer during the year $2000 .^{22}$ We exclude the five goods in the category 9 at the 1-digit level of disaggregation (titled, 'Commodities and transactions not classified elsewhere'), which are likely to bundle together very heterogeneous commodities. As a result, we are able to obtain up to 162 different unit prices (one for each importer in the dataset) for each of the 744 different goods in the SITC-4 categorisation.

Our first proxy for the length of quality ladders utilises the interdecile ratio of unit prices for each of the goods in the SITC-4 categorisation (this is more robust to outliers than using simply the max-to-min price ratio). In that regard, we take unit prices as proxies for the intrinsic qualities of a particular good, and the extreme price ratios are accordingly viewed as proxies for the length of quality ladders of goods. Our second proxy for the length of quality ladders uses coefficients of variation of the distribution of unit prices for each of the SITC-4 goods. The underlying idea for this measure is that goods featuring longer quality ladders should, in general, also display a more 'dispersed' distribution of unit prices. ${ }^{23}$

20. See also Hallak (2006) for related evidence showing that rich countries import relatively more from countries that produce higher-quality goods, and Fieler (2007) for evidence that unit prices correlate positively with the importer's income per head.

21. Of course, unit prices/values should only be taken as an imperfect proxy of the intrinsic quality of the commodity, since factors other than quality may also be affecting unit prices (for example, the degree of horizontal differentiation across industries, heterogeneous transport costs, trade tariffs).

22. We choose to calculate unit prices using only the year 2000 for two different reasons. First, it avoids problems that may arise from comparing unit prices at different points in time. Second, and more importantly, using the last year available seems the most promising alternative in terms of proxying the length of ladders according to the nature of nonhomotheticities in our model. This is because the poorest country in 2000 was roughly as poor as the poorest one in 1962, whereas the richest economy in 2000 was substantially richer than the richest one in 1962.

23. In Table A1, available on the online appendix, we group all the SITC-4 sectors/goods into their corresponding 1-digit sector (excluding sector 9). Therein we report the average values of the interdecile unit price ratios and the average values of coefficients of variation of unit prices. Except for sector 2, Table A1 seems to point to the common perception that the quality ladders of primary goods tend to be shorter than those of manufacturing products (i.e. sectors 5 to 8 ). 
The previous section concludes that countries that specialise in the production of goods with longer quality ladders should see their total value of exports increase more strongly when world income rises (and viceversa). We assess this prediction resorting to a reduced-form approach by conducting the following regression:

$$
\Delta X_{i, t}=\delta+\gamma\left(\Delta Y_{t}^{w} \times \text { Ladder }_{i, t}\right)+\mu_{t}+\eta_{i}+v_{i, t} .
$$

In (17), $\Delta X_{i, t}$ equals the percentage growth of the total value of exports by country $i$ in year $t$ and $Y_{t}^{w}$ is the percentage growth of world income per head in year $t$. The variable Ladder $r_{i, t}$ measures the (weighted) average length of ladder of the bundle of goods exported by country $i$ in year $t$ : we build this variable by weighing the length of ladder of each SITC-4 product by the share of that product in the total value of exports of country $i$ in period $t$. Our model thus predicts $\gamma>0 .{ }^{24}$

Columns (1)-(5) in Table 1 show the results of different versions of (17) when we measure the length of ladders of goods by the interdecile unit price ratios. Column (1) and (2) use all countries in the panel, the former including country fixed effects and the latter excluding them: in both cases the estimates are positive and significant. In (3) we exclude countries from the OPEC from the regression in case oil exporters may have a large impact on the results (in particular, given that our sample includes years when the oil shocks occurred); the previous results remain essentially intact. Results also remain unaltered when we exclude Latin American economies from the sample in column (4) - in this case, the rationale is that many of these economies have gone through severe macroeconomic and external crises during '80s and '90s, including large devaluations of their currencies, which could importantly affect their exports for reasons other than those highlighted by our model. Finally, in (5) we exclude the OECD countries to have some feeling about whether our results are crucially driven by comparing developed economies to less developed ones; as we can readily observe, results still remain essentially unaffected when we restrict the sample in such a way.

In columns (6)-(10) we replicate the same regressions using the coefficients of variation of unit prices. Although the significance of the estimates is lower than in (1)(5), and in (6) we (marginally) fail to reach significance at $10 \%$ level, all the estimates carry the expected sign and, moreover, their magnitudes exhibit a similar pattern to those in columns (1)-(5).

Although results in Table 1 should be interpreted as capturing only a reduced-form correlation between the variables of interest, it is interesting to get a sense of the size of this association. The average growth rate of world per-capita income $\left(\Delta Y_{t}^{w}\right)$ in the sample is $2 \%$. The mean and the standard deviation of the interdecile price ratios are equal to 6.5 and 5.6, respectively. Thus, the coefficient in column (1) implies that, when world income per capita rises $2 \%$, countries whose exports' ladders are one standard deviation above the mean will experience a growth rate of their exports $1.8 \%$

24. Notice that since (17) includes year fixed effects $\left(\mu_{t}\right)$, we do not need to include $\Delta Y_{t}^{w}$ as an additional independent variable because such effect will be fully captured by each $\mu_{t}$. 
above that of economies whose exports' ladders are one standard deviation below the mean. ${ }^{25}$

Viewed from a longer run perspective, our model argues that, if countries' comparative advantage remain constant over time, the initial pattern of specialisation may lead to uneven future exports growth when goods differ in their scope for quality upgrading. In particular, within a context of world income per capita growth, countries initially specialised in long-ladder goods should exhibit a higher rate of growth of exports in future years. Table 2 looks at how economies' initial specialisation correlates with future exports growth in a context of positive world income growth. We calculate the initial specialisation by measuring the ladder length of each country using their export shares across products during the first five years of the sample (i.e., we use their export shares during years 1962-67), while the length of ladders for each SITC-4 good are still being proxied by their unit prices in the last year in the sample (i.e. year 2000). ${ }^{26}$ Next, we average the rate of growth of exports of each country using only years of positive world income growth for the subsample 1971-2000. Finally, we regress those average growth rates on countries' initial specialisation. In other words, we run the following regression: $\Delta X_{i,{ }^{\prime} 71-{ }^{\prime} 00}=\alpha+\beta$ Ladder $_{i,{ }^{\prime} 62-{ }^{\prime} 67}+\varepsilon_{i}$, where the year subindexes denote the period over which the averages are computed (in the case of $\Delta X_{i,{ }^{\prime} 71-{ }^{\prime} 00}$, using only those years for which $\Delta Y_{t}^{w}>0$ ). The reason for using only years of positive growth is that we seek to find a positive coefficient in the regression. More precisely, we wish to test whether economies that exported longladder goods during the first five years of the panel have subsequently experienced a faster rate of growth of their exports during years of positive world income growth. ${ }^{27}$ As done before in Table 1, we run regressions including all countries, and subsequently excluding OPEC, Latin American and OECD countries. All the regressions yield positive coefficients, consistent with the predictions of our model,

25. When using the coefficient in column (3), this differential in the growth rates of exports rises to $2.2 \%$. Bearing in mind that the median growth rate of exports in the sample equals $9.5 \%$, these magnitude seem fairly considerable. Finally, results are of a very similar order of magnitude when using the estimates based on the coefficient of variation of unit prices - i.e. columns (6)-(10).

26. The construction of the ladder lengths is in line with the logic of our model, where goods' potential of quality upgrading is the feature that really matters for long-run exports growth, and the process of quality upgrading itself materialises over time as world productivity expands and world income rises accordingly.

27. Notice that, different from (17), in this regression we are not including as a regressor an interaction term, but only the (initial) length of ladders. This implies that when restricting to years of positive growth we should expect to find a positive $\beta$. In principle, we could also run the same (restricted) regression using only years with negative growth of world income per capita, expecting to find a negative coefficient instead of a positive one. However, the lack of observations is a problematic issue here. There are only three years in the sub-sample 1971-2000 when world income per head experienced negative growth (years 1975, 1982, and 1991). Moreover, the rate of growth of world income per head in those two years is not so different from zero (the lowest is recorded in 1982 when it was $-0.5 \%$ ). 
TABLE 1. Cross-country panel regressions.

\begin{tabular}{|c|c|c|c|c|c|c|c|c|c|c|}
\hline & \multicolumn{10}{|c|}{ Dependent Variable: rate of growth of total exports of each country } \\
\hline & (1) & (2) & (3) & (4) & (5) & (6) & (7) & (8) & (9) & (10) \\
\hline Inter action term versi on $1\left(Y_{w} \times\right.$ Ladder length) & $\begin{array}{c}0.079 \\
(0.036)^{* *}\end{array}$ & $\begin{array}{c}0.065 \\
(0.019)^{* * *}\end{array}$ & $\begin{array}{c}0.098 \\
(0.035)^{* * *}\end{array}$ & 0.099 & $\begin{array}{c}0.087 \\
(0.047)^{*}\end{array}$ & & & & & \\
\hline Inter action term versi on $2\left(Y_{w} \times\right.$ Ladder length $)$ & & & & & & $\begin{array}{r}0.86 \\
(0.63)\end{array}$ & $\begin{array}{c}0.80 \\
(0.44)^{*}\end{array}$ & $\begin{array}{c}1.24 \\
(0.65)^{* *}\end{array}$ & $\begin{array}{c}1.35 \\
(0.68)^{* *}\end{array}$ & $\begin{array}{c}1.23 \\
(0.72)^{*}\end{array}$ \\
\hline Country fixed effects & YES & NO & YES & YES & YES & YES & NO & YES & YES & YES \\
\hline Excludes OPEC countries & NO & NO & YES & YES & YES & NO & NO & YES & YES & YES \\
\hline Excludes Latin American countries & No & No & NO & YES & YES & NO & NO & No & YES & YES \\
\hline Excludes OECD countries & NO & No & No & NO & YES & NO & NO & NO & No & YES \\
\hline Observations & 5331 & 5331 & 4943 & 4384 & 3393 & 5331 & 5331 & 4943 & 4384 & 3393 \\
\hline Number of countries & 162 & 162 & 150 & 135 & 108 & 162 & 162 & 150 & 135 & 108 \\
\hline R - Squared & 0.20 & 0.20 & 0.21 & 0.19 & 0.16 & 0.20 & 0.20 & 0.21 & 0.19 & 0.16 \\
\hline
\end{tabular}

Robust absolute $t$-statistics clustered at the country level in parentheses. All data is for years 1963-2000. All regressions include year dummies and a constant term. Interaction term version 1 uses inter-decile unit price ratio to proxy for length of ladder of SITC-4 products. Interaction term version 2 uses the coefficient of variation of unit prices to proxy for length of ladder of SITC-4 products. We only include countries with at least 10 observations in the panel. * significant at $10 \%$; ** significant at 5\%; *** significant at $1 \%$.

TABLE 2. Future exports growth regressions.

\begin{tabular}{|c|c|c|c|c|c|c|c|c|}
\hline & \multicolumn{8}{|c|}{$\begin{array}{l}\text { Average growth of exports using years of positive world income growth } \\
\text { S ample: years } 1971-2000\end{array}$} \\
\hline & (1) & $(2)$ & (3) & (4) & (5) & (6) & $(7)$ & $(8)$ \\
\hline Initial ladder length (1962-66) version 1 & $\begin{array}{r}0.065 \\
(0.15)\end{array}$ & $\begin{array}{l}0.215 \\
(0.15)\end{array}$ & $\begin{array}{l}0.215 \\
(0.17)\end{array}$ & $\begin{array}{r}0.151 \\
(0.21)\end{array}$ & & & & \\
\hline Initial ladder length (1962-66) version 2 & & & & & $\begin{array}{c}0.75 \\
(1.72)\end{array}$ & $\begin{array}{c}2.88 \\
(1.64)^{*}\end{array}$ & $\begin{array}{c}2.80 \\
(1.76)^{*}\end{array}$ & $\begin{array}{c}2.27 \\
(1.85)\end{array}$ \\
\hline Excludes OPEC countries & NO & YES & YES & YES & NO & YES & YES & YES \\
\hline Excludes Latin American countries & NO & NO & YES & YES & NO & NO & YES & YES \\
\hline Excludes OECD countries & NO & NO & NO & YES & NO & No & NO & YES \\
\hline Observations & 140 & 129 & 114 & 89 & 140 & 129 & 114 & 89 \\
\hline
\end{tabular}

Initial ladder length version 1 uses inter-decile unit price ratio to proxy SITC-4 products ladders, weighting these ratios by the average exports shares of each product during years 1962-66. Initial ladder length version 2 uses the coeffients of variation of unit prices, weighting in a similar way as in version 1 . Dependent variable is the average growth of total exports by each country during years in the sample in which world income per head displays positive growth. Robust t-statistics in parentheses. All regressions include a constant term. * significant at $10 \%$;* significant at $5 \%$; *** significant at $1 \%$.

although we fail to reach significance at $10 \%$ level in the majority of cases, as the standard errors are quite large. ${ }^{28}$

\section{Conclusion}

We have proposed a model of international trade with nonhomothetic preferences based on comparative advantages that are unrelated to the stage in the process of development in which countries are. We showed that even when no single country enjoys a clear absolute advantage over any other country and productivity changes are uniform and identical in all countries, international trade may still be the source of income divergence when nonhomothetic preferences and quality ladders are jointly taken into account. In particular, countries' incomes will diverge when comparative

28. In columns (2) and (3), the coefficient would become significant at $10 \%$ if the test were conducted against the 'alternative hypothesis' of $\beta>0$; that is, if the test were conducted only against the upper tail of the distribution. 
advantage induce patterns of specialisation that do not offer the same scope for improvements in terms of quality upgrading of final products in the long run.

Our model also points out that worldwide uniform productivity growth generates two distinct types of product cycle phenomena. The first is an international product cycle phenomenon à la Linder-Vernon, where over time one economy takes on the production of goods previously produced by another economy. The second - which is novel to our model - is a regional product cycle that occurs within each good and within each economy: rising world income makes all economies engage in the production of newer goods of higher quality (so as to satisfy the increasing demand for high qualities by wealthier consumers).

A key insight of our model is that quality upgrading attracts consumer expenditure. Here, we have assumed a rather stylised combination of preferences and cost of quality upgrading, so that luxuries are univocally determined over the entire development path. However, our framework is in principle more general than that particular structure, and as such can help in shedding light on other empirical observations such as the highly nonmonotonic shapes that observed Engel curves often take (see, eg., Lewbel 2006). These nonmonotonicities are hard to reconcile with the most common current nonhomothetic specifications (e.g. hierarchical of "0/1" preferences). In our setup, income variations could lead to richer spending dynamics (possibly nonmonotonic) if, given the specific cost structure adopted, quality upgrading occurred faster for certain goods only over a certain range of incomes, and for others over alternative ones.

We have focused on productivity shocks that are uniform across all sectors. However, sectoral shocks may also have an impact on consumer expenditure across types of goods in case these shocks lead to adjustments in the distribution of optimal qualities. This mechanism may, for instance, help in refining the excessive volatility of consumption predicted by most of asset pricing models, which owing to the use of homothetic preferences tend to underestimate (or even neglect) the effects of quality upgrading on marginal utility of consumption.

Finally, here we have discussed how our theory may shed light on historical cases where comparative advantage emerged exogenously, for example as a result of geographical conditions. A different long-run issue, widely analysed in the empirical literature, relates to why bilateral trade rises with the GDP of trading partners. This topic is the subject of ongoing research by combining our preference specification with the notion that comparative advantages tend to emerge (or become more pronounced) as wealthier consumers start demanding higher qualities of final goods.

\section{Appendix A: First-Order Conditions for Consumption Choice in $\mathbf{H}$}

The optimisation problem in (5) yields the following first-order conditions (where $\mu$ represents the Lagrange multiplier associated to the budget constraint and $\left\{\lambda_{v}\right\}_{v \in \mathcal{V}}$ 
denote those associated to the constraints $\left.\left\{q_{v} \geq 1\right\}_{v \in \mathcal{V}}\right)$.

$$
\begin{aligned}
\ln \left(\frac{\beta_{v} w}{\kappa^{-1} \alpha(v) q_{v}^{\eta(v)}}\right)-\eta(v)+\lambda_{v} & =0, \forall v \in \mathcal{V} ; \\
\frac{q_{v}}{\beta_{v}}-\mu & =0, \forall v \in \mathcal{V} ; \\
q_{v}-1 \geq 0, \lambda_{v} \geq 0, \text { and } \lambda_{v}\left(q_{v}-1\right) & =0, \forall v \in \mathcal{V} ; \\
1-\int_{\mathcal{V}} \beta_{v} d v & =0 .
\end{aligned}
$$

From (A.2), it follows that $\beta_{v}=q_{v} / \mu$. Then, replacing this last expression into (A.4) leads to $\int_{\mathcal{V}} q_{z} d z=\mu$, from where the condition (6) immediately obtains by using again (A.2). By using the condition (6), we can rewrite (A.1) as

$$
\lambda_{v}=\eta(v)+\ln [\alpha(v) / w]-\ln \kappa+\ln Q+[\eta(v)-1] \ln q_{v} .
$$

The expression in (A.5) will be used in several of the following proofs.

\section{Appendix B: Optimal Consumption Choice in F}

Bearing in mind Assumption 1, we can write down the optimisation problem faced by a representative individual from $\mathrm{F}$ as follows:

$$
\begin{aligned}
\max _{\left\{x_{v q}^{*}\right\}_{(v, q) \in \mathcal{V} \times \mathcal{Q}}} & U^{*}=\int_{\mathcal{V}} q_{v}^{*} \ln \left(\frac{w^{*} \beta_{v}^{*}}{p_{v}^{*}}\right) d v \\
\text { subj. to: } & \int_{\mathcal{V}} \beta_{v}^{*} d v=1, \\
& q_{v}^{*} \geq 1, \text { for all } v \in \mathcal{V}, \\
& p_{v q}=\kappa^{-1} q^{\eta(v)} \alpha(v), \text { for all }(v, q) \in \mathcal{V} \times \mathcal{Q} .
\end{aligned}
$$

Expression in (4) holds for $x_{v q}^{*}$ in a similar fashion as for $x_{v q}$. Hence, we can re-state the problem specified above in terms of $q_{v}^{*}$ and $\beta_{v}^{*}$, as it was previously done for $\mathrm{H}$. In this way, we can obtain the following FOC, which constitute the analogous versions for $\mathrm{F}$ of (6) and (A.5), respectively.

$$
\begin{aligned}
\beta_{v}^{*} & =\frac{q_{v}^{*}}{\int_{\mathcal{V}} q_{z}^{*} d z}, \forall v \in \mathcal{V}, \\
\lambda_{v}^{*} & =\eta(v)+\ln \left[\alpha(v) / w^{*}\right]-\ln \kappa+\ln Q^{*}+[\eta(v)-1] \ln q_{v}^{*} .
\end{aligned}
$$

Given (B.2) and (B.3), all the ensuing results found in Section 3 follow through in qualitative terms. In particular, we can derive functions $\left\{q_{v}^{*}\right\}_{v \in \mathcal{V}}$ and $\left\{\beta_{v}^{*}\right\}_{v \in \mathcal{V}}$ displaying identical qualitative properties as their counterparts in H. Furthermore, we can similarly find the threshold $\underline{\kappa}^{*}$ for the worldwide aggregate-productivity 
parameter, which splits $\mathrm{F}$ in the regimes of subsistence-economy and moderneconomy; both exhibiting analogous properties as described for $\mathrm{H}^{29}$ Finally, likewise for $\mathrm{H}$ in Corollary 1, for $\mathrm{F}$ the following holds:

COROLlaRY B.1. $\operatorname{Let} \theta^{*}(v) \equiv \int_{0}^{v} \beta_{z}^{*} d z$. Then: (i) for all $\kappa \in\left(0, \underline{\kappa}^{*}\right): \partial \theta^{*}(v) / \partial \kappa=$ $0, \forall v \in \mathcal{V}$; and (ii) for all $\kappa \geq \underline{\kappa}^{*}: \partial \theta^{*}(v) / \partial \kappa>0, \forall v \in \mathcal{V}$, with strict inequality if $v<1$.

\section{Appendix C: Omitted Proofs}

Proof of Lemma 1. Suppose $q_{\underline{v}}<q_{\bar{v}}$. Since by definition $q_{\underline{v}} \geq 1$, then $q_{\bar{v}}>1$, hence (A.5) paired with (A.3) yield,

$$
\eta(\underline{v})+\ln [\alpha(\underline{v}) / w]-\ln (\kappa / Q) \geq 0,
$$

and

$$
\eta(\bar{v})+\ln [\alpha(\bar{v}) / w]-\ln (\kappa / Q)+[\eta(\bar{v})-1] \ln q_{\bar{v}}=0
$$

Thus,

$$
\eta(\underline{v})+\ln \alpha(\underline{v}) \geq \eta(\bar{v})+\ln \alpha(\bar{v})+[\eta(\bar{v})-1] \ln q_{\bar{v}} .
$$

This last equality in turn leads to

$$
[\eta(\bar{v})-\eta(\underline{v})]+\ln [\alpha(\bar{v}) / \alpha(\underline{v})]+[\eta(\bar{v})-1] \ln q_{\bar{v}} \leq 0,
$$

which cannot possibly hold if $q_{\bar{v}}>1$, as its left-hand side would then be strictly positive. Therefore, it must be the case that $q_{\underline{v}} \geq q_{\bar{v}}$.

Suppose now $q_{\underline{v}}=q_{\bar{v}}>1$. In this case, (A.5) in conjunction with (A.3) yield,

$$
\eta(\underline{v})+\ln \alpha(\underline{v})+[\eta(\underline{v})-1] \ln q_{\bar{v}}=\eta(\bar{v})+\ln \alpha(\bar{v})+[\eta(\bar{v})-1] \ln q_{\bar{v}}=0 .
$$

This last equality in turn leads to:

$$
-[\eta(\bar{v})-\eta(\underline{v})](1+\ln q \bar{v})=\ln [\alpha(\bar{v}) / \alpha(\underline{v})] .
$$

However, this last equality cannot possibly hold since its right-hand side is strictly positive, while the left-hand side is negative. As a result, $q_{\underline{v}}>q_{\bar{v}}$ must necessarily hold when $q_{\underline{v}}>1$.

Proof of Lemma 2. Part (i). Proof follows immediately from noting that whenever $0<\kappa<\underline{\kappa}, q_{v}=1$ must hold for all $v \in \mathcal{V}$. Thus, whenever $\kappa \in(0, \underline{\kappa}), \partial q_{v} / \partial \kappa=0$ for all $v \in \mathcal{V}$.

Part (ii). Firstly, notice that, since $q_{v}=1$ must hold for all $v \notin \mathcal{L}$, a proof analogous to that of Part (i) of this Lemma applies for all goods in this subset.

29. From Section 4, it is straightforward to observe that, given Assumption $1, \underline{\kappa}^{*}=\underline{\kappa}$. 
Secondly, since for any $v \in \mathcal{L}$, we may write $q_{v}$ as: $:^{30}$

$$
q_{v}=\left[\frac{e^{\eta(0)} \alpha(0)}{e^{\eta(v)} \alpha(v)}\right]^{\frac{1}{\eta(v)-1}} q_{0}^{\eta(0)-1}
$$

differentiating (C.1) with respect to $\kappa$ yields:

$$
\frac{d q_{v}}{d \kappa}=\frac{\eta(0)-1}{\eta(v)-1}\left[\frac{e^{\eta(0)} \alpha(0)}{e^{\eta(v)} \alpha(v)}\right]^{\frac{1}{\eta(v)-1}}\left(q_{0}\right)^{\frac{\eta(0)-\eta(v)}{\eta(v)-1}} \frac{d q_{0}}{d \kappa}, \text { for all } v \in \mathcal{L}
$$

Using again (C.1), the equation above can be written:

$$
\frac{d q_{v}}{d \kappa}=\frac{\eta(0)-1}{\eta(v)-1} \frac{q_{v}}{q_{0}} \frac{d q_{0}}{d \kappa}, \text { for all } v \in \mathcal{L} .
$$

(Since $\eta(\cdot)>1$, notice that $d q_{v} / d \kappa$ and $d q_{0} / d \kappa$ must then share the same sign, for all $v \in \mathcal{L})$. Next, given that $Q=1-\tilde{v}(\kappa)+\int_{0}^{\tilde{v}(\kappa)} q_{z} d z$, it follows that:

$$
\frac{d Q}{d \kappa}=\int_{0}^{\tilde{v}(\kappa)} \frac{d q_{z}}{d \kappa} d z=\frac{1}{q_{0}}\left(\int_{0}^{\tilde{v}(\kappa)} \frac{\eta(0)-1}{\eta(z)-1} q_{z} d z\right) \frac{d q_{0}}{d \kappa} .
$$

Applying (A.5) to $v=0$ when $\lambda_{0}=0$ yields,

$$
q_{0}=\left[a(0) e^{\eta(0)} Q\right]^{-\frac{1}{\eta(0)-1}} \kappa^{\frac{1}{\eta(0)-1}} .
$$

Thus:

$$
\frac{d q_{0}}{d \kappa}=\frac{q_{0}}{\eta(0)-1} \frac{Q}{\kappa}\left(1-\tilde{v}+\int_{0}^{\tilde{v}(\kappa)} \frac{\eta(z)}{\eta(z)-1} q_{z} d z\right)^{-1}>0 .
$$

Therefore, from (C.2) it follows that $d q_{v} / d \kappa>0$, for all $v \in \mathcal{L}$ must also hold. Finally, from (C.2) it immediately follows that

$$
d q_{\underline{v}} / d \kappa=d q_{\bar{v}} / d \kappa=0 \text { if } \underline{v}, \bar{v} \notin \mathcal{L}
$$

and

$$
d q_{\underline{v}} / d \kappa>d q_{\bar{v}} / d \kappa=0 \text { if } \underline{v} \in \mathcal{L} \text { and } \bar{v} \notin \mathcal{L} .
$$

For $\underline{v}, \bar{v} \in \mathcal{L}$, such that $\underline{v}<\bar{v},($ C.2) leads to

$$
\frac{d q_{\underline{v}}}{d \kappa}=\frac{\eta(0)-1}{\eta(\underline{v})-1} \frac{q_{\underline{v}}}{q_{0}} \frac{d q_{0}}{d \kappa}>\frac{\eta(0)-1}{\eta(\bar{v})-1} \frac{q_{\bar{v}}}{q_{0}} \frac{d q_{0}}{d \kappa}=\frac{d q_{\bar{v}}}{d \kappa},
$$

since by assumption $\eta(\underline{v})<\eta(\bar{v})$ and, from Lemma $1, q_{\underline{v}}>q_{\bar{v}}$.

30. See Lemma D.2 in online Appendix D for a derivation of (C.1). 
Proof of Proposition 1. Part (i). Proof follows immediately from noting that whenever $0<\kappa<\underline{\kappa}, \partial q_{v} / \partial \kappa=0$ must hold for all $v \in \mathcal{V}$. Thus, whenever $\kappa \in(0, \underline{\kappa})$, $\partial \beta_{v} / \partial \kappa=0$ for all $v \in \mathcal{V}$.

Part (ii). Firstly, suppose that that $\underline{v} \notin \mathcal{L}$. Then, from Lemma 1 it must also be that $\bar{v} \notin \mathcal{L}$. Hence from Lemma $2 d q_{\underline{v}} / d \kappa=d q_{\bar{v}} / d \kappa=0$, implying in turn that $d \beta_{\underline{v}} / d \kappa=d \beta_{\bar{v}} / d \kappa$. Secondly, suppose that $\underline{v} \in \mathcal{L}$. Considering the definition of average quality, taking logarithms and differentiating (6) with respect to $\kappa$ yields,

$$
\left(d \beta_{v} / d \kappa\right) / \beta_{v}=\left(d q_{v} / d \kappa\right) / q_{v}-(d Q / d \kappa) / Q
$$

Using (C.2), we can write

$$
\frac{d q_{\underline{v}}}{d \kappa} \frac{1}{q_{\underline{v}}}=\frac{\eta(0)-1}{\eta(\underline{v})-1} \frac{d q_{0}}{d \kappa} \frac{1}{q_{0}}>\frac{\eta(0)-1}{\eta(\bar{v})-1} \frac{d q_{0}}{d \kappa} \frac{1}{q_{0}} \geq \frac{d q_{\bar{v}}}{d \kappa} \frac{1}{q_{\bar{v}}} ;
$$

where the last (weak) inequality stems from the fact that if $\bar{v} \in \mathcal{L}$ then (C.2) holds for $\bar{v}$, whereas if $\bar{v} \notin \mathcal{L}$ then $d q_{\bar{v}} / d \kappa=0$. It follows then that

$$
\frac{d \beta_{\underline{v}}}{d \kappa} \frac{1}{\beta_{\underline{v}}}>\frac{d \beta_{\bar{v}}}{d \kappa} \frac{1}{\beta_{\bar{v}}} .
$$

Finally, using (C.4), the claim trivially follows by noting that, from Lemma 1 in conjunction with (6), $\beta_{\underline{v}}>\beta_{\bar{v}}$ must always hold.

Proof of Corollary 1. Preliminarily, recall $\int_{z \in \mathcal{V}} \beta_{z} d z=1$, which implies $\int_{0}^{1}\left(\partial \beta_{z} / \partial \kappa\right) d z=0$.

Part (i). Claim immediately follows since, whenever $\kappa<\underline{\kappa}, \partial \beta_{z} / \partial \kappa=0$ for all $z \in \mathcal{V}$.

Part (ii). Note first that when $\kappa \geq \underline{\kappa}$, the set $\mathcal{J} \neq \emptyset$. As a result, from Proposition 1, Part (i), it follows that $\int_{0}^{v}\left(\partial \beta_{z} / \partial \kappa\right) d z>\int_{v}^{1}\left(\partial \beta_{z} / \partial \kappa\right) d z$. Then, since $\int_{0}^{v}\left(\partial \beta_{z} / \partial \kappa\right) d z+\int_{v}^{1}\left(\partial \beta_{z} / \partial \kappa\right) d z=0$, we must necessarily have that $\int_{0}^{v}\left(\partial \beta_{z} / \partial \kappa\right) d z>0$.

\section{References}

[1] Alcala, Francisco (2009). "Comparative Advantage across Goods and Product Quality." DT02/09, BBVA.

[2] Benedetti Fasil, Cristiana and Teodora Borota (2010). "World Trade Patterns and Prices: The Role of Productivity and Quality Heterogeneity." Uppsala University Working Paper Series, 2010:7.

[3] Bertola, Giuseppe, Reto Foellmi and Josef Zweimuller (2006). Income Distribution in Macroeconomic Models. Princeton: Princeton University Press.

[4] Brooks, Eileen L. (2006). "Why Don't Firms Export More? Product Quality and Colombian Plants.” Journal of Development Economics, 80, 160-178. 
[5] Dornbusch, Rudiger, Stanley Fischer and Paul A. Samuelson (1977). "Comparative Advantage, Trade, and Payments in a Ricardian Model with a Continuum of Goods." American Economic Review, 67, 823-839.

[6] Fajgelbaum, Pablo D., Gene M. Grossman and Elhanan Helpman (2009). "Income Distribution, Product Quality, and International Trade.” NBER Working Paper No. 15329.

[7] Feenstra, Robert C., Robert E. Lipsey, Haiyan Deng, Alyson C. Ma and Hengyong Mo (2005) "World Trade Flows: 1962-2000.” NBER Working Paper No. 11040.

[8] Fieler, Ana C. (2007). "Quality Differentiation in International Trade: Evidence from the Demand and Supply Sides.” Mimeo, New York University.

[9] Flam, Harry and Elhanan Helpman (1987). "Vertical Product Differentiation and NorthSouth Trade." American Economic Review, 77, 810-822.

[10] Foellmi, Reto, Christian Hepenstrick and Josef Zweimuller (2008). "Income Effects in the Theory of Monopolistic Competition and International Trade." Mimeo, University of Zurich.

[11] Foellmi, Reto, Tobias Wuergler and Josef Zweimuller (2009). "The Macroeconomics of Model T." CEPR Discussion Paper No. 7612.

[12] Grossman, Gene M and Elhanan Helpman (1991). "Quality Ladders and Product Cycles." Quarterly Journal of Economics, 106, 557-586.

[13] Hall, Douglas (1959). Free Jamaica, 1838-1865: An Economic History. New Haven: Yale University Press.

[14] Hallak, Juan C. (2006). "Product Quality and the Direction of Trade." Journal of International Economics, 68, 238-265.

[15] Hallak, Juan C., and Peter K. Schott (2010). "Estimating Cross-Country Differences in Product Quality." Quarterly Journal of Economics, Forthcoming.

[16] Higman, Barry W. (2005). Plantation Jamaica, 1750-1850: Capital and Control in a Colonial Economy. Jamaica: University of the West Indies Press.

[17] Iacovone, Leonardo and Beata S. Javorcik (2008). "Shipping Good Tequila Out: Investment, Domestic Unit Values and Entry of Multi-Product Plants into Export Markets.” Mimeo, Oxford University.

[18] Imbs, Jean and Romain Wacziarg (2003). "Stages of Diversification." American Economic Review, 93, 63-86.

[19] Khandelwal, Amit (2010). “The Long and Short (of) Quality Ladders." Review of Economic Studies, 77, 1450-1476.

[20] Lewbel, Arthur (2006). Engel Curves. The New Palgrave Dictionary in Economics, 2nd Edition.

[21] Linder, Staffan B. (1961). An essay on trade and transformation. Uppsala: Almqvist \& Wiksell.

[22] Lucas, Robert E. (1988). “On the Mechanics of Economic Development.” Journal of Monetary Economics, 22, 3-42.

[23] Maddison, Angus (2008). Statistics on World Population, GDP and Per Capita GDP, 1-2006 AD. Website: http://www.ggdc.net/maddison.

[24] Matsuyama, Kiminori (2000). "A Ricardian Model with a Continuum of Goods under Nonhomothetic Preferences: Demand Complementarities, Income Distribution, and 
North-South Trade." Journal of Political Economy, 108, 1093-1120.

[25] Newton, Jorge (1966). Historia de la Sociedad Rural Argentina. Buenos Aires: Editorial Goncurt.

[26] Prebisch, Raul (1950). The Economic Development of Latin America and Its Principal Problems. United Nations, Econ. Comm. Latin America.

[27] Rapaport, Mario (1988). Economia e Historia: Contribuciones a la Historia Economica Argentina. Buenos Aires: Libreria Editorial Tesis.

[28] Sheridan, Richard B. (1973). Sugar and Slavery: An Economic History of the British West Indies 1623-1775. Baltimore: The John Hopkins University Press.

[29] Schott, Peter K. (2004). "Across-Product versus Within-Product Specialization in International Trade." Quarterly Journal of Economics, 119, 647-678.

[30] Singer, Hans W. (1950). "The Distributions of Gains between Investing and Borrowing Countries.” American Economic Review, 40, 473-485.

[31] Stokey, Nancy L. (1991). "The Volume and Composition of Trade between Rich and Poor Countries." Review of Economic Studies, 58, 63-80.

[32] Taylor, M. Scott (1993). "Quality Ladders and Ricardian Trade.” Journal of International Economics, 34, 225-243.

[33] Verhoogen, Eric A. (2008). "Trade, Quality Upgrading and Wage Inequality in the Mexican Manufacturing Sector.” Quarterly Journal of Economics, 123, 489-530.

[34] Vernon, Raymond (1966). "International Investment and International Trade in the Product Cycle.” Quarterly Journal of Economics, 80, 190-207. 